\title{
A SMART MV/LV-STATION THAT IMPROVES POWER QUALITY, RELIABILITY AND SUBSTATION LOAD PROFILE
}

\author{
Josco C.P. KESTER \\ ECN Intelligent Energy Grids - NL \\ kester@ecn.nl \\ J.F.G. (Sjef) COBBEN \\ Liander - NL \\ sjef.cobben@alliander.com \\ Erik C.W. DE JONG \\ KEMA Consulting - NL \\ Erik.deJong@kema.com
}

\author{
Peter J.M. HESKES \\ ECN Intelligent Energy Grids - NL \\ heskes@ecn.nl \\ Gerard SCHOONENBERG \\ EATON Electric - NL \\ GerardSchoonenberg@Eaton.com \\ Ben J. WARGERS \\ IMTECH VONK - NL \\ ben.wargers@imtech.nl
}

\author{
J. J. (Sjaak) Kaandorp \\ ECN Intelligent Energy Grids - NL \\ kaandorp@ecn.nl \\ Dmytro MALYNA \\ Exendis B.V. - NL \\ d.malyna@exendis.com
}
A.J.F. (Ton) DALMEIJER
ALFEN - NL
td@alfen.nl

\begin{abstract}
Because of the increasing penetration of dispersed generation and developments in the power demand, the power flows in $L V$ and $M V$ distribution grids will increasingly fluctuate in the near future. To manage these fluctuations while maintaining power quality and reliability, a Smart MV/LV-station has been designed by a Dutch consortium. A prototype of this station will be built and tested. Tests will take place both in the Flex Power Grid Lab in Arnhem (NL) and in a live test grid of the Dutch grid operator Liander. Results of the lab test and the live grid demonstration are expected during 2009 and 2010. First simulation results show a significant reduction of harmonic voltages and resonances, as well as a peak load reduction of $30 \%$.
\end{abstract}

\section{THE NEED FOR A SMART MV/LV-STATION}

Due to the increasing penetration of dispersed generation and peak loads there is a need to increase the intelligence of the components in the medium and low voltage network. Also the increase in sensibility of devices for the quality of voltage and the increasing number of power quality related problems are a reason to look to more functionality in the $\mathrm{MV} / \mathrm{LV}$-station.

In general, intelligent components are needed to:

- Get information about and be able to influence the power flows in the medium and low voltage networks

- Get information about and be able to influence the voltage profile in these networks

- Increase the immunity against power quality problems, such as harmonics, voltage dips, flicker

- Reduce the unavailability (minutes of interruption)

- Recognise illegal connections to the network

- Be able to create microgrids which will be able to work autonomously to increase the reliability as needed.

\section{DESIGN OF THE SMART MV/LV-STATION}

A Smart MV/LV-station is built to handle these items. A schematic picture is shown in Fig. 1.

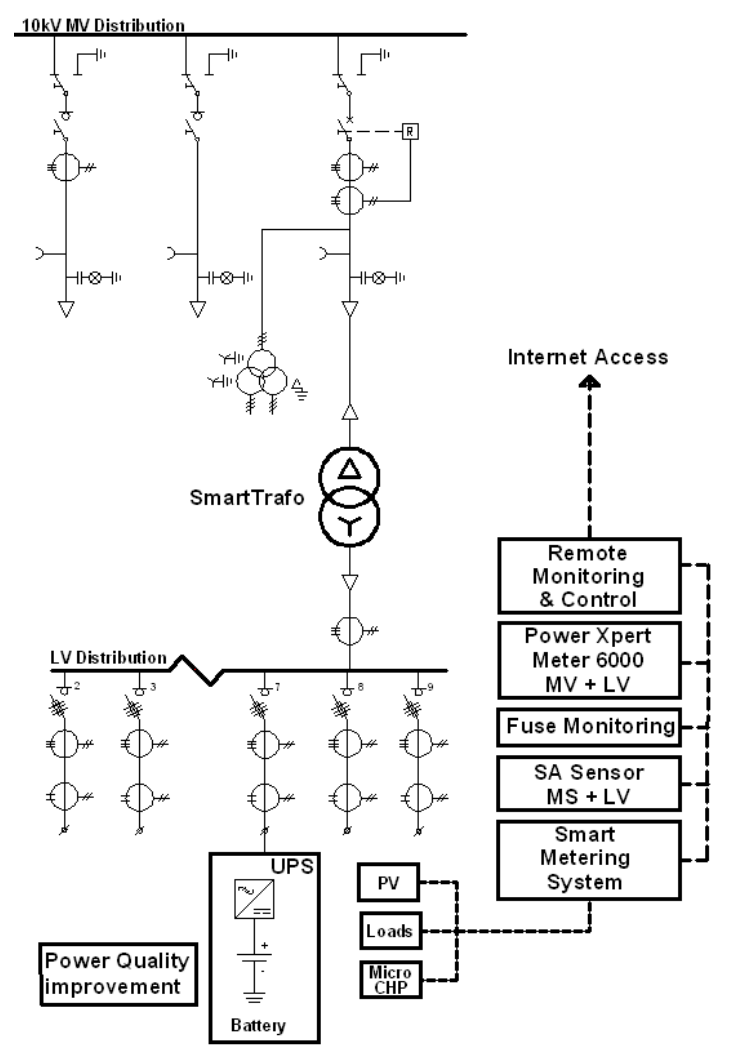

Figure 1 Schematic picture of the Smart Substation

Some of the additional features of the Smart MV/LVstation are:

1. control of voltage pollution

2. Demand Response, using an agents based control system (PowerMatcher)

3. a system for local control and remote monitoring 
4. an electricity storage system, consisting of a battery and a bi-directional inverter (ESI)

5. stepless control of the voltage level on the LV bus bar, performed by a smart transformer (SmartTrafo)

6. bidirectional communication between home appliances and the Smart MV/LV-station, using a home automation system (XanuraHome).

\section{CONTROL OF VOLTAGE POLLUTION}

Electricity distribution grids of the near future will be loaded with more and more electronic power converters. This replacement of old fashion loads for modern domestic appliances with power electronic grid coupling, will increase capacitive loads that can cause resonances. Also it can decrease damping, which could increase resonances and harmonic pollution [1].

A very attractive way to reduce harmonics is the use of Resistive Harmonic Damping (RHD) [2], [3]. This approach will damp harmonics and is also very effective for damping of resonances in the grid. To reduce voltage distortion on the feeders RHD is implemented as ancillary service in the electricity storage system in the Smart Substation.

For reduction of harmonics the best location of the RHD is at the end or in the middle of a feeder [4]. As in this project the first priority is the damping of possible resonances in the grid and the second priority the reduction of harmonics, the RHD will be placed in the substation, at the beginning of the feeder. The advantage of this location is that only one RHD can do the job for the whole distribution grid below the station. While this location will not result in an optimal performance for harmonic damping, it is expected that it can be at least sufficient for damping of resonances. First simulations have shown promising results for this solution.

\section{DEMAND RESPONSE}

As energy consumption and peak demand in the distribution grid increase, the distribution grid operator is faced with capacity shortages. Through Demand Response (DR) a grid operator can reduce the peak demand and thus defer the resulting investments in infrastructure.

To implement Demand Response the PowerMatcher control concept for supply and demand matching (SDM) is included in the Smart MV/LV-station. PowerMatcher is a market-based control concept that finds an optimal match between preferences of producers, consumers and the power grid [5]. In the Smart MV/LV-station the PowerMatcher is used to control the power flows from the battery in the station itself, as well as power flows from flexible appliances and generators in the houses connected to the substation.

\section{MONITORING AND CONTROL}

At the heart of the Smart MV/LV-station is a monitoring and control system that communicates with various sensors inside the distribution station and with appliances and sensors of customers. An additional internet connection is provided, so that the grid operator can remotely monitor the station.

\section{ELECTRICITY STORAGE SYSTEM}

An electrical energy storage system consisting of a battery and a bidirectional inverter (ESI) ensures many of the power quality features of the Smart MV/LV-station. The battery is capable of storing $30 \mathrm{~kW} \cdot \mathrm{h}$ of electrical energy. The ESI charges and discharges the battery. It supplies to the grid: active and reactive powers in the range $0 \ldots 60 \mathrm{~kW}$ and $-60 \ldots+60 \mathrm{kVAr}$ respectively; a pulsating active power; and harmonic currents by means of emulating the shunting resistances per phase [3]. Next to the aforementioned functions the ESI can operate in island mode as a UPS with the limited power of $60 \mathrm{~kW}$.

The battery is discharged during periods of peak demand and charged during the off-peak periods. The decision about charging or discharging the battery is made by the PowerMatcher Supply Demand Matching system, based on the grid power balance and the state of charge of the battery, as determined by the Battery Management System (BMS).

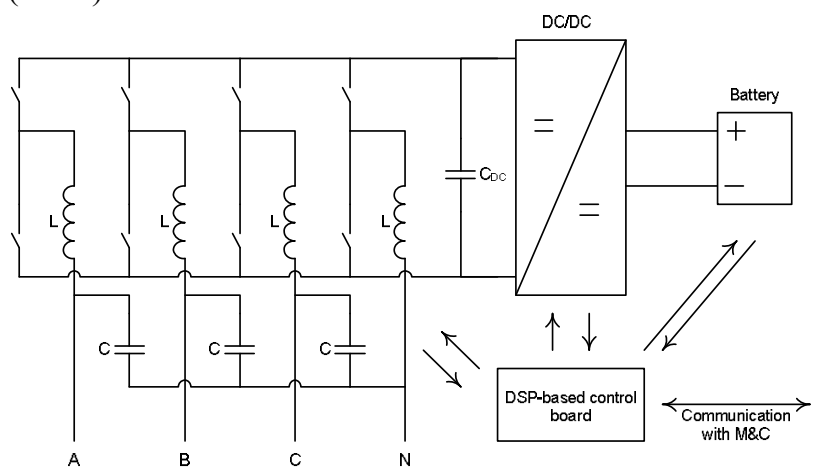

Figure 2. Simplified electrical diagram of the ESI

"Fast control" actions, are performed locally by the ESI using information of the internal sensors, which are directly connected to a DSP-based controller (see Fig. 3). The DSPbased controller communicates with the Monitoring and Control PLC (M\&C), and the PowerMatcher via a digital interface.

\section{STABILISED LV GRID AT VARYING 10 KV}

Due to an increasing energy demand large voltage variations in the $10 \mathrm{kV}$ distribution grid of energy suppliers could occur. Especially with long $10 \mathrm{kV}$ lines or with a large number of local power generation units like CHP units, the $400 \mathrm{~V}$ user voltage quality can no longer be guaranteed. The main problem is the fixed transformer winding ratio of the $10 / 0.4 \mathrm{kV}$ distribution transformers. As a consequence voltage variations in the $10 \mathrm{kV}$ grid will be transferred to the $400 \mathrm{~V}$ grid, resulting in lowered 
secondary voltage during periods of high energy demand and higher voltage level during periods of low energy demand.

To keep the secondary voltage level stable at $400 \mathrm{~V}$, a SmartTrafo is included in the Smart MV/LV-station. The SmartTrafo adapts the transformer winding ratio to keep the LV grid stabilised. Basically the selection between the transformer fixed tap positions has to be made gradual instead of with fixed steps. In order to comply with the requirements for harmonics and $\cos \varphi$, the IGBT quasi Graetz bridge topology with controlled duty cycle (PWM) is the most appropriate one for the SmartTrafo. Consequently the SmartTrafo inside the Smart MV/LVstation regulates the $400 \mathrm{~V}$ secondary voltage by continuous adaptation of the transformer winding ratio. It will stabilise the $400 \mathrm{~V}$ grid voltage independent of the varying $10 \mathrm{kV}$ voltage or other $400 \mathrm{~V}$ user load variation.

\section{COMMUNICATION WITH HOMES}

To support the Demand Response features of the Smart $\mathrm{MV} / \mathrm{LV}$-station a bidirectional communication link is established between the station and individual home appliances, such as Combined Heat Power Systems (CHP) or Photo Voltaic cells (PV). This communication link can be made by connection an appropriate smart metering system with a Home Automation system. Measured values are amongst other CHP state, room temperature, heat buffer temperature and current PV power output.

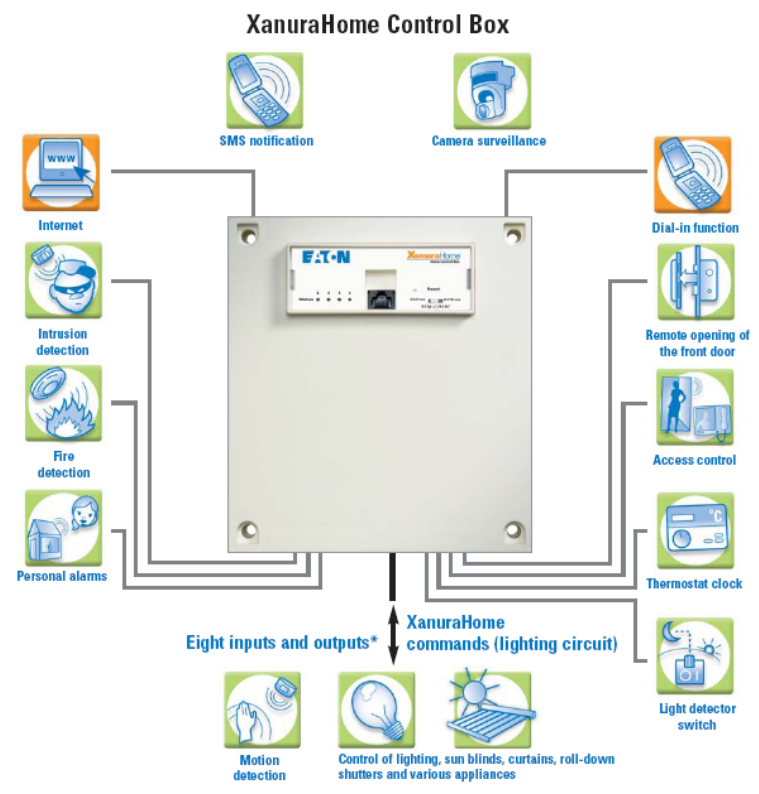

Figure 3. XanuraHome Control Box, used for communication with home appliances

In this project, in each of controlled houses the XanuraHome system is installed including the XanuraHome Control Box (HCB), see Fig. 3. The XanuraHome system is especially designed for private consumers. It is easy to install in both new and existing buildings. Phase and neutral are used for communication over the lighting network. By fitting transmitting and receiving components as interface to the individual home appliances, commands can be sent from the XanuraHome Control Box over the existing lighting network anywhere in the house.

\section{SIMULATION RESULTS}

First simulation results are available for Resistive Harmonic Damping (RHD) and for the Demand Response (DR) features. In Fig.4 the effect of RHD on harmonic voltage pollution from Matlab/Simulink simulation, is depicted.

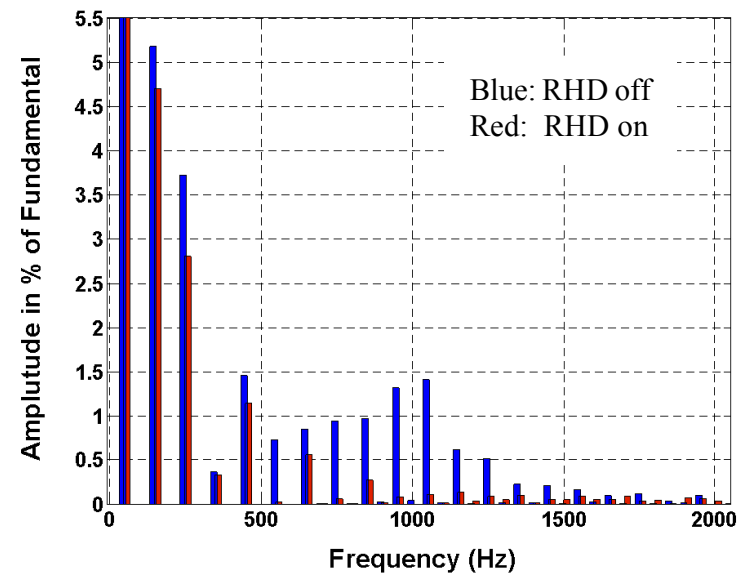

Figure 4. Simulation results of RHD on one phase of the voltage

Simulations of the Demand Response features supplied by the PowerMatcher control mechanism also show promising results. In a simulation study [5] this was investigated using a cluster of 40 houses, all connected to the same segment of a LV distribution network. 20 houses are heated by heat pumps, the other 20 houses by $\mu$ CHP units. Electric storage is present in the form of a battery.
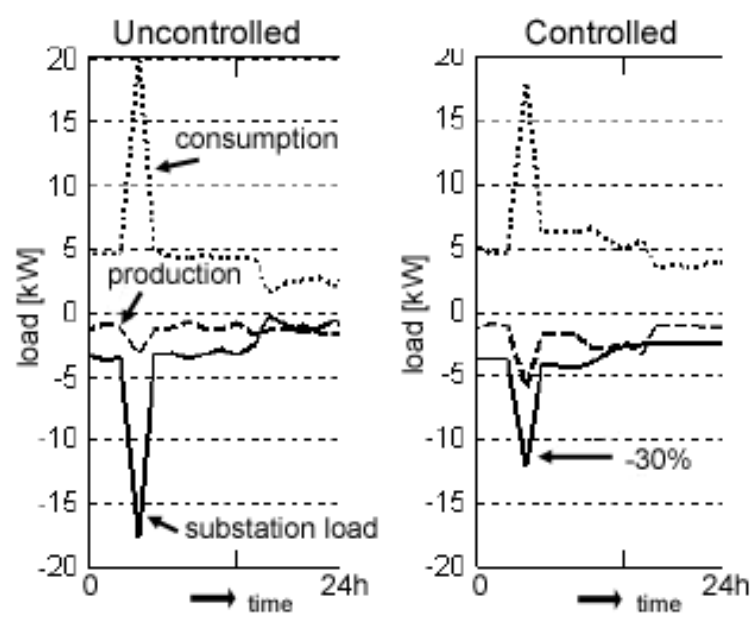

Figure 5. Simulation results for demand response in a cluster of 40 houses with heat pumps and ¿CHP units. 
Fig. 5 shows the simulation results for this scenario. Each graph contains the lines for consumption, production and substation load. The left graph shows the uncontrolled situation, the right graph shows the PowerMatcher controlled case. In the controlled case the peak demand is reduced by $30 \%$.

\section{OPERATIONAL TESTS IN FPGLAB}

The operational tests will be performed in the Flex Power Grid Lab [6], a medium-voltage power electronic laboratory situated in Arnhem (NL). The objective of the tests is to ensure that the Smart MV/LV-station complies with the specified requirements as set out in the project scope.

The operational tests are intended to verify the design of the Smart MV/LV-station with regards to its performance under normal operating conditions, overload conditions, islanding conditions, adverse power quality conditions, abnormal conditions and transient fault conditions. The tests shall demonstrate that:

- The Smart MV/LV-station functions properly and autonomously with no failures, correct voltage and current waveforms and correct operation of all internal circuits under the various specified test conditions.

- The voltage and currents stresses, especially during adverse power quality conditions, are within the capabilities of the individual sub-assembly components and other internal circuits.

- The cooling provided is adequate and no component is overheated, even under the worst temperature and operating conditions.

- The protection characteristic is maintained despite the effect of temperature and adverse operating conditions, in particular loss of monitoring and control functionality.

Furthermore, the operational tests are intended to:

- Explore the limits of the Smart MV/LV-station.

- Estimate the achievable robustness of the Smart $\mathrm{MV} / \mathrm{LV}$-station.

- Estimate the achievable reliability of the Smart MV/LVstation, partially through autonomous island operation.

- Indicate the contribution of the Smart MV/LV-station in: decreasing the peak load in congested MV grid segments; supplying reactive power; and improving power quality.

The acceptance criteria for the performed tests are aligned with those prescribed in the prevailing (inter)national standards for distribution stations and equipment.

\section{FIELD TEST IN A LIVE GRID}

Mid 2009 the Smart MV/LV-station will be placed in the network of Liander, a Dutch grid operator. There the ultimate test of the above mentioned functionalities will be made. During the next 6 months in 2009 the data in the field will be analysed and the behaviour of the MV/LV-station will be studied. Important to analyse is the capability of the substation to influence the power flows, power quality (harmonics, voltage level etc) and to get management ready information about the status of the substation and the connected customers installations. Results of all the tests will be available end of 2009 or beginning 2010 .

\section{CONCLUSIONS}

A Smart MV/LV-station has been designed that improves power quality, reliability and substation load profile. In 2009 tests will be performed in the FPGLab and in a live network of Liander. These tests will show the performance of the station.

Preliminary simulations have shown that there is a significant damping of harmonic voltages and resonances. Beside this the demand response features can contribute to a $30 \%$ reduction of the peak load.

\section{ACKNOWLEDGEMENTS}

The authors wish to thank SenterNovem and the Dutch ministry of Economic Affairs for their financial contribution to the project, under the IOP-EMVT-program.

\section{REFERENCES}

[1] J.H.R. Enslin et al, 2004, "Harmonic Interaction Between Large Numbers of Photovoltaic Inverters and the Distribution Grid", IEEE Transact. on Power Electronics Vol. 19.

[2] H. Akagi, "New trends in active power line conditioners", IEEE Trans. on Ind. Appl. vol. 32.

[3] W.R. Ryckaert et al, 2005, Reduction of the Voltage Distortion with a Converter Employed as Shunt Harmonic Impedance, IEEE.

[4] K. Wada et al, 2002, "Considerations of a Shunt Active Filter Based on Voltage Detection for Installation on a Long Distribution Feeder", IEEE Trans. on Ind. Appl. Vol. 38 .

[5] J.K. Kok, C. Warmer and I.G. Kamphuis, 2005, "PowerMatcher: multiagent control in the electricity infrastructure", Proceedings of the 4th Int. Joint Conf. on Autonomous Agents and Multi-Agent Systems ( $A A M A S^{\prime}$ '05), ACM Press, Industry Track Vol., 75-82.

[6] E.C.W. de Jong, E.M. de Meulemeester, P.J.M. Heskes, 2008, "Design and realisation of a unique MV converter implemented in a new power electronic equipment test laboratory for emerging $\mathrm{MV}$ applications", Proceedings Power and Energy Society General Meeting - Conversion and Delivery of Electrical Energy in the 21st Century, IEEE, 1-4. 